\title{
The structural validity of the innovative work behaviour questionnaire: Comparing competing factorial models
}

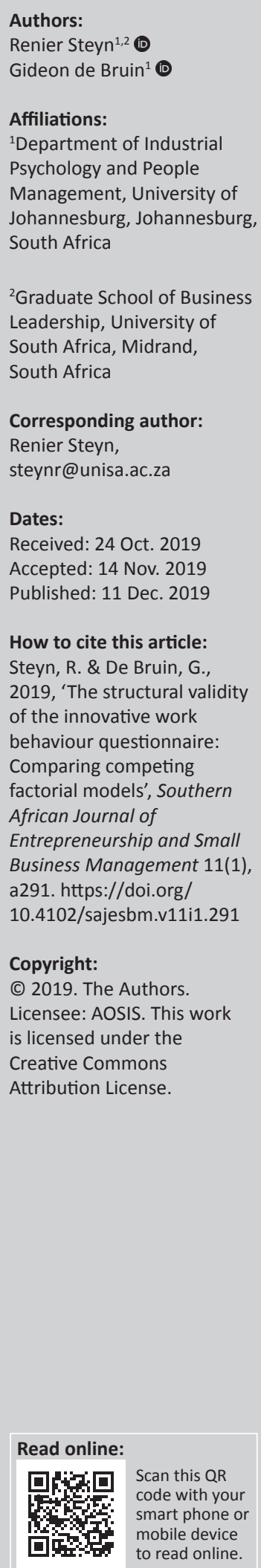

Background: Innovation is about central organisational sustainability and is fundamentally centred in individuals.

Objectives: Understanding and building theory on innovative work behaviour (IWB), as well as the parallel measurement thereof, is a prerequisite to the development of models for enhancing IWB. Most theorists propose IWB as a sequential process involving steps such as exploration, generativity, investigation, championing and application. These steps are also reflected in the design of IWB measurements. In this study, the theorised step-structure of IWB, as proposed by Kleysen and Street in 2001, is tested - relying on general descriptive statistics and applying exploratory and confirmatory factor analyses, with five different factorial structures tested.

Methods: Complete records for more than 3000 respondents on the IWB measure were available. The results revealed that exploration and generativity occur more often than investigation, championing and application, alerting theorists to the dwindling effect of creative ideas and also to the hierarchical nature of the steps embedded in IWB. With regard to structure, the results revealed that the IWB steps were correlated, not orthogonal, and unlikely to be sequential as theorised. The initial steps of IWB (exploration and generativity) are therefore linked to the latter steps (investigation, championing and application), implying that employees are cognisant of the latter steps when engaging in the former.

Results: The results of this study suggest reconsidering the segmented stepwise thinking regarding IWB. It also has important practical implications for stimulating IWB: Enabling individuals to manage the latter 'steps' of the IWB may well encourage the creativity and curiosity associated with the former 'steps'.

Conclusion: The research provides important insights into the nature of IWB, informing theoretical models using data-driven information.

Keywords: innovative work behaviour; South Africa; factorial validity; factor analyses; structural equation modelling.

\section{Introduction}

According to literature, there is consensus on the fact that innovation constitutes a key source of competitiveness, and that it forms an essential element of organisational success (Bos-Nehles, Renkema \& Janssen 2017; Sanz-Valle \& Jiménez-Jiménez 2018; Veenendaal 2015). The task of effecting innovation is often left to the research and development departments (Scott \& Bruce 1994). Unlike the case of those who work in research and development teams, innovative behaviour by general employees is often perceived as an extra role or as a discretionary action, and is often not formally, directly or even indirectly recognised in organisations (Janssen 2000). However, motivating general employees to implement innovative work behaviour (IWB) should be an important task of managers, as previous research has identified the management practices that inspire such employee behaviours (Bos-Nehles et al. 2017; Sanz-Valle \& Jiménez-Jiménez 2018; Veenendaal 2015). This may be essential to an organisation's sustainability.

The conceptualisation, as well as valid measurement of IWB, is disparate. Without the exact conceptualisation and accurate measurement of IWB, models and theories on precursors to IWB, as well as the benefits of IWB, cannot be tested empirically. Although most prominent theorists on IWB (De Jong \& Den Hartog 2010; Janssen 2000; Kleysen \& Street 2001; Scott \& Bruce 1994) perceive IWB as a sequence of activities (stages), they differ on how they define the broad construct, and subsequently also the number of stages it comprises. Perhaps, most alarming is the fact that the theorised concepts do not materialise as discrete stages when tested empirically 
(De Jong \& Den Hartog 2010; Janssen 2000; Kleysen \& Street 2001; Scott \& Bruce 1994), with researchers identifying less complexity than theoretically proposed, often reporting a single construct to be representative of IWB. ${ }^{1}$ Scott and Bruce (1994) explain the measurement of IWB as only a single construct because of the fact that innovation is characterised by discontinued activities, where employees may be involved in several of these activities simultaneously. De Jong and Den Hartog (2010), as well as Janssen (2000), reference Scott and Bruce's (1994) explanation, when they account for finding less complex models.

In this article, the evolution of the IWB concept will be discussed with reference to the way the concept is defined, conceptualised (as a multi-stage process) and measured. The model of IWB, as proposed by Kleysen and Street (2001), will be tested, based on a sample size much larger than the one used in the original study, and using five competing fit models, compared to the single model used in the original study. Kleysen and Street (2001) only tested for a five-factor model, while in this study additional tests were run for a higher second-order model, an orthogonal five-factor model, a bi-factor model, as well as a single factor model.

This article contributes to the IWB literature in two ways. Firstly, it presents a detailed conceptualisation of the complex concept of IWB and portrays how it is presented and measured by some of the most prominent researchers in this field. Secondly, it exposes the structure of IWB, incorporating the theorised structure proposed by Kleysen and Street (2001) using five different modelling techniques. This article provides a deeper insight into the factors that make up IWB, and could be considered as relevant, as it provides a more coherent picture of IWB and how it is measured.

The article consists of five parts. Firstly, existing literature relevant to IWB is reviewed, specifying how IWB is defined, conceptualised and measured. Next, the research method is offered and the data analysis techniques are explained. Then the results are presented and summarised. This is followed by a discussion of the results, linking the results to the literature. The article concludes with a discussion of the theoretical and managerial implications, as well as by providing directions for future research.

\section{Literature review}

The literature review focusses on the seminal IWB work by De Jong and Den Hartog (2010), Janssen (2000), Kleysen and Street (2001), as well as Scott and Bruce (1994). While focussing on these authors, the valuable work of Farr and Ford (1990), Kanter (1988), as well as West and Farr (1989) is acknowledged. In the first part of this literature review, definitions of the IWB concept will be presented and analysed. Next, the proposed structure of IWB will be presented.

\footnotetext{
1.Scott and Bruce (1994), and later Janssen (2000), collapsed the three stages of IWB that they theoretically proposed into a single construct when measuring it. Kleysen and Street (2001) were also unable to substantiate the five stages of IWB that they and Street (2001) were also unable to substantiate the five stages of IWB that they
proposed, and just like De Jong and Den Hartog (2010), who proposed four stages, proposed, and just like De Jong and Den Hartog (2010), who pr
eventually reported on less complex measurement models.
}

The measurement of IWB will then be discussed, together with some psychometric properties of the different proposed instruments.

\section{Definitions of innovative work behaviour}

The definitions of IWB provided below build on each other and are in many ways related, with the later researchers often referring to earlier attempts to define IWB. Scott and Bruce (1994) do not define innovation explicitly in their article, but rather conceptualise it as something more than creativity, where the distinction is substance. They state that creativity relates to the production of novel and useful ideas, whereas innovation has to do with the production or adoption of beneficial ideas and idea implementation. It is therefore not only novelty and new knowledge but also incorporates the reworking of products or processes, and bringing the idea into effect. Janssen (2000:288) defines IWB as 'the intentional creation, introduction and application of new ideas within a work role, group or organization, in order to benefit role performance, the group, or the organization'. Later, Janssen (2000:288) states that 'these extrarole [sic] behaviours refer to discretionary employee actions which go beyond prescribed role expectations, and are not directly or explicitly recognized by the formal reward system'. Many follow Janssen's (2000) definition of IWB, including Bos-Nehles et al. (2017), Sanz-Valle and Jiménez-Jiménez (2018), as well as Veenendaal (2015). When defining IWB, Kleysen and Street (2001) borrow from West and Farr (1989) and explain IWB as 'all individual actions directed at the generation, introduction and or application of beneficial novelty at any organisational level' (p. 285). They state that this novelty relates to new products, technologies and processes, aimed at significantly enhancing organisational efficiency and effectiveness. Lastly, when defining IWB, De Jong and Den Hartog (2010) reference the work of Janssen (2000), as well as Scott and Bruce (1994), and claim that IWB 'encompass(es) a broad set of behaviours related to the generation of ideas, creating support for them, and helping their implementation' (p. 23). They then present the definition of Farr and Ford (1990) to describe IWB as 'an individual's behaviour that aims to achieve the initiation and intentional introduction (within a work role, group or organization) of new and useful ideas, processes, products or procedures' (p. 24).

\section{The structure of innovative work behaviour}

The aforementioned definitions describe IWB in terms of an input-throughput-output model (Kast \& Rosenzweig 1972), being deterministic (Teece 2018), directed to specific outcomes or even being path-dependant (Levy 1994). The specific outcomes are presented as positive and being beneficial to the organisation's success. Although all the authors share a multi-dimensional and multi-stage perspective of IWB, it will become clear from what follows that the authors differ in their understanding of the nature and number of dimensions that IWB comprises. 
Scott and Bruce (1994) propose IWB as a multi-stage process, consisting of distinct activities associated with each stage. The first stage involves creativity, where ideas or solutions, which may be novel or adopted, are generated. Following generation, sponsorship for the idea is necessary, and individuals try to build coalitions in order to further the idea. In the last stage, the innovative individual completes the process by operationalising the idea. This process seems to follow from the work of Kanter (1988). Kanter proposes a four-stage process, involving idea generation, coalition building, idea realisation and transfer or diffusion. The last stage of 'spreading the model - the commercialisation of the product, the adoption of the idea' (Kanter 1988:512) seems to be incorporated in idea realisation, as proposed by Scott and Bruce (1994).

Scott and Bruce (1994), however, state - in contradiction to their presentation of a sequential list of activities - that innovation should for all intents and purposes be regarded as a set of discontinuous activities rather than discrete and sequential stages and that individuals may at any time be involved in any of these activities.

Janssen (2000) follows Scott and Bruce's (1994) conceptualisation of IWB and also explains it as a multifaceted behaviour consisting of three behavioural tasks, namely, idea generation, idea promotion and idea realisation. Janssen (2000) explains that innovation begins with idea generation, which is often instigated by perceived work-related problems, incongruities, discontinuities and emerging trends. Next, the idea needs to be endorsed by capable sponsors, so as to provide the necessary assistance for implementation.

The last element involves realisation, which includes experimentation, and ultimately the application of the idea. Janssen (2000) states that in the case of small innovations, one individual may be involved in all of these activities, while more complex innovations usually require area-specific expertise. Janssen (2000) supports the notion that the innovation processes are often characterised by discontinuous activities and that 'individuals can be expected to be involved in any combination of these behaviors at any time', as proposed by Scott and Bruce (1994:582). The development work conducted by Janssen (2000) is widely acknowledged, including by Lukes and Stephan (2017).

Kleysen and Street (2001) confirm the idea that IWB is a multi-dimensional construct and, following an extensive literature, review five elements as essential in individual innovation, namely, opportunity exploration, generativity, information investigation, championing and application. Opportunity exploration involves the act of discovering or learning more about innovation opportunities. This involves paying attention to the environment and gathering information about possible opportunities, and therefore looking for possibilities, and recognising innovation opportunities as such. Generativity relates to the formulation of creative ideas that refer to beneficial changes and solutions to problems. However, it goes beyond pure creativity and also involves ideas being categorised, associations being drawn between ideas and ideas being combined in new ways. Information investigation is concerned with experimentation, thus giving form to specific innovation and trying out new ideas. This requires the accurate formulation of the concept, piloting it and also evaluating the outcome thereof. Championing involves the sociopolitical element of innovation. To mobilise the necessary resources and to implement the idea or solution, influencing and persuading are necessary, as change normally involves the challenging of old ways, as well as risk-taking.

Application forms the final and apex element of innovation behaviour and signifies the adoption of the innovation. This involves the implementation of the solution, reorganising or modifying present systems and ultimately a broad-based acceptance of the new direction. Kleysen and Street (2001) proposed a model in which each of the factors is related to each other - which is fundamentally based on their confidence in their literature review.

De Jong and Den Hartog (2010) stated that theoretically much work has been conducted to distinguish between various dimensions and different stages of the innovation process. They then presented a four-stage scheme of IWB, focussing on idea exploration, generation, championing and implementation. Idea exploration could be seen as the first step in the innovative process, where an individual identifies a problem or opportunity, with the urge to overcome the problem or make use of the opportunity. This step identifies problems or opportunities often related to the constant change in the environment, and may include issues related to current products, services or processes. Idea generation is the next proposed element of IWB. It relates to the idea of solving the identified problems or making use of the opportunities. It often involves the combination and reorganisation of information and concepts in different ways, therefore 'rearranging already existing pieces into a new whole' (De Jong \& Den Hartog 2010:24). Idea championing is an essential element of innovation as most ideas need to be promoted because of resistance caused by the requirement to change existing ways of doing things, and by the unknown effect of the envisaged benefits of its implementation. Often it involves individuals finding support for creative ideas through their informal roles and building coalitions within the organisation. Idea implementation follows only after enough support and enthusiasm for the idea have been obtained. This implies operationalising the idea, which requires putting sufficient effort into rolling out the idea and being results-oriented. It could include creating a culture of innovation and organisational learning. De Jong and Den Hartog (2010), however, are aware of the modelling of IWB as a multidimensional construct, and therefore tested two hypotheses in presenting their measure of IWB. They claimed that: (1) the four elements contribute to an overall construct (IWB) and (2) the four elements are distinct dimensions of IWB. In this article, similar hypotheses will be tested. 
The various aforementioned authors are in agreement as to the basic structure of IWB, although they differ on the exact number of stages through which IWB evolves. In many respects, this may be a matter of semantics, or at best a more refined look at the phenomena. In the discussion which follows, more details on the way the authors conceptualise the stage will become clear, as the items they include in their questionnaires reveal a significant part of their thinking.

\section{Measuring innovative work behaviour}

The way IWB is measured reflects the conceptualisation of the concept. Given below are four measures of IWB, stating the number of items included, the response format used, the items themselves, as well as some information on the reliability and validity of the instruments.

Scott and Bruce (1994) presented a six-item questionnaire, in which supervisors rated employees on a five-point Likerttype scale, ranging from 'not at all' to 'an exceptional degree'. The first item read as follows (Scott \& Bruce 1994:606-607): '[s] earches out new technologies, processes, techniques and/ or product ideas' [sic].

Although references to Scott and Bruce (1994) are very common, their scale of IWB is not often used. Lukes and Stephan (2017) used some of the items in developing their own questionnaire, while Lin and Lee (2017) used the questionnaire in an adapted form. A Cronbach's alpha on this original scale was 0.89 (Scott \& Bruce 1994). Lin and Lee (2017) reported an $\alpha$-value of 0.86 on their adapted scale. With respect to validity, Scott and Bruce (1994) found a correlation of $0.33(p<0.001)$ between an objective measure of innovation, based on each respondent's innovative history, and the supervisors' ratings of IWB. They suggest that this provides some assurances as to the validity scale. Furthermore, Lin and Lee (2017) reported, using confirmatory factor analysis (CFA), that employees' innovative behaviour, organisational learning and work engagement scales each had standardised factor loading larger than 0.7 , which they considered as evidence of good convergent validity of each scale.

Janssen (2000) proposed nine items with which to measure IWB, which can be self-reports or ratings of employees by direct supervisors. Respondents were asked to indicate how often they (or in the case of supervisors, employees) could be associated with particular behaviours in the workplace. The response format was a seven-point scale ranging from 'never' (1) to 'always' (7). The item and the aspects they assess are presented by Janssen (2000). The first item read as follows: 'Creating new ideas for difficult issues (idea generation)' (p. 292). The first three items assessed idea generation, the next three assessed idea promotion, whereas the last three focussed on idea realisation.

Janssen's measure was recently used by Amir (2015), as well as by Javed et al. (2017). Janssen (2000) reported Cronbach's alphas of 0.95 for the self-rated and 0.96 for the leader-rated scores of IWB. Amir (2015) does not provide any reliability data, but Javed et al. (2017) reported an alpha of 0.70 . Regarding validity, Janssen (2000) reported that the intercorrelations between the three aspects of IWB ranged from 0.84 (between idea generation and idea realisation) to 0.87 (between idea generation and idea promotion) for the leader-reports, and from 0.76 (between idea generation and idea realisation) to 0.85 (between idea promotion and idea realisation) for the self-reports. Given these high intercorrelations, and following Scott and Bruce (1994), idea generation, idea promotion and idea realisation were perceived to combine additively to create an overall scale of IWB.

Amir (2015) replicated the proposed structure of Janssen (2000), reporting that a three-dimensional model showed a better fit than two-dimensional and single models.

Kleysen and Street's (2001) questionnaire comprises 14 items. Respondents were asked to rate themselves with regard to each statement on a six-point scale, varying from 'never' (1) to 'always' (6). All the questions had the same prefix, namely, 'In your current job, how often do you'. The first item's individual questions read as follows (Kleysen \& Street 2001:293): ' ... look for opportunities to improve an existing process, technology, product, service or work relationship?' The first three items were related to exploration. Items 4 and 5 referred to generativity, with the consecutive items, in groups of three, relating to information investigation, championing and application.

Kleysen and Street (2001) reported a reliability coefficient higher than 0.70 for all the sub-scales, which is acceptable (Hair et al. 2010). The alpha for opportunity exploration was 0.719. For generativity, it was the same (0.719) and for information investigation it was 0.802. In the case of championing, the alpha was 0.893 , and for application it was 0.796. Hebenstreit (2003) reported an alpha of 0.948 , when using all the items. $\mathrm{Lu}$ and $\mathrm{Li}$ (2010) found a two-factor solution, and reported the Cronbach's alpha values as 0.860 for each of these factors. Wojtczuk-Turek and Turek (2013) also reported on a two-factor solution, with values of 0.880 and 0.890 respectively. The results of the CFA performed by Kleysen and Street (2001) did not lend empirical support to the theorised structure. However, these authors argued that as the items were developed to represent a well-defined domain, this provided construct validity to the measure. Although Kleysen and Street (2001) suggested the use of the items as a single measure of innovation behaviour, they also stated that their research demonstrates the multidimensionality of the construct. Hebenstreit (2003), following this stance, reported on a single factor. Lu and Li (2010), on the other hand, reported two factors (innovative idea generation and innovative idea implementation), as do Wojtczuk-Turek and Turek (2013), who refer to these factors as: (1) recognising problems and initiating activities, as well as (2) generating ideas and implementing them. 
De Jong and Den Hartog (2010) stated that the aim of their questionnaire was to capture the multi-dimensional measures of individual innovative behaviour, as such an instrument was not available at the time, and owing to the fact that the construct is theoretically treated as multi-dimensional. The questionnaire contained 10 items, to be completed by supervisors. The responses ranged from 'never' (0) to 'always' (6). All the items have the same prefix, namely, 'How often does this employee ...'. The first question reads as follows (De Jong \& Den Hartog 2010:29): ' . . . pay attention to issues that are not part of your daily work?' Idea exploration (Items 1 and 2), generation (Items 3, 4 and 5), championing (Items 6 and 7) and implementation (Items 8, 9 and 10) were the dimensions assessed by the questionnaire.

The De Jong and Den Hartog (2010) instrument is used by De Spiegelaere et al. (2014), Niesen et al. (2018), as well as by Polston-Murdoch (2015). Veenendaal (2015) adopted items from De Jong and Den Hartog (2010) and Kleysen and Street (2001) when they developed their own measure. De Jong and Den Hartog (2010) reported a Cronbach's alpha coefficient of 0.90 for idea exploration, 0.88 for idea generation, 0.95 for idea championing and 0.93 for idea implementation. These coefficients are consistently high and acceptable (Hair et al. 2010). Atitumpong and Badir (2017) reported an alpha of 0.880 , when using all the items. Reporting on two dimensions, De Spiegelaere et al. (2014) reported alphas of 0.910 and 0.930 , respectively. Similarly, Niesen et al. (2018) reported on two factors, with values of 0.870 and 0.900 , respectively, with 0.870 when using all the items.

Applying CFA as well as simple correlation analysis, De Jong and Den Hartog (2010) concluded that the four elements contributed to an overall construct of IWB, rather than being four distinct dimensions of IWB. Atitumpong and Badir (2017) reported on a single factor, while De Spiegelaere et al. (2014) identified two factors, which they named idea generation and idea implementation. Niesen et al. (2018) also reported on two factors, which they call idea generation and idea implementation. Furthermore, De Jong and Den Hartog (2010) tested three hypotheses relating to the criterion validity of the instrument, all of which were supported. Most importantly, scores on the IWB Scale correlated positively with innovative outcomes.

From the aforementioned, some differences among the authors regarding the stage-type conceptualisation of IWB is visible. Although Scott and Bruce (1994) presented their measure as a single scale (six items), the items seem sequential. The others present items linked to dimensions, which also appear sequential. The authors agree on the perceived multi-dimensional nature of IWB but disagree on the number of these dimensions. Also, researchers attempt to replicate these theorisations empirically applying factor analyses, often resulting in them resurging back to simpler or single models, based on their empirical findings. There seems to be a dissonance between the theory and the empirical evidence, which is (inadequately) ascribed to IWB comprising discontinued activities and individuals being involved in several of these activities simultaneously - as originally suggested by Scott and Bruce (1994). These inadequate explanations suggest a theoretical flaw in the understanding of the structure of IWB. Bos-Nehles et al. (2017:1229) echoed this and stated that '... knowledge about IWB ... is fragmented and inconsistent' and 'as such, organisations may be restricted in their ability to innovate ... because they do not know how to trigger employees in a way that will encourage them to engage in IWB'.

The aim of the study was to achieve more clarity on the conceptualisation of IWB through testing different measurement models to reveal which data-driven model best explains the phenomena. Using increasingly advanced modelling techniques may reveal the precise structure of IWB.

\section{Method \\ Population and sampling}

The target population consisted of all employees and all organisations. However, availability, accessibility, proximity and cost necessitated a focus on South African organisations. Only medium to large organisations were targeted. To gain access to these organisations, Master of Business Leadership students were recruited to gain permission to conduct research in these medium to large organisations. In most cases, access to organisations was granted to the students based on their relationships with specific organisations. In most cases, they were employed by these companies. The sampling of corporate entities was therefore based on convenience.

The students were required to draw a random sample of employee lists in the organisations to which they received access. Each student was requested to deliver 60 completed questionnaires. To achieve this, they started off by drawing a sample of 60 and then, depending on the response rate, drew fresh samples from the original list until they reached the target of 60 . Although the sampling process was not perfect, it inclined towards a random sample.

\section{Measurement instrument}

Kleysen and Street's (2001) 14 item IWB questionnaire, discussed above, was used. As stated above, respondents were asked to rate themselves with regard to the 14 statements on a six-point scale, ranging from 'never' (1) to 'always' (6). The first three items measured exploration, with items 4 and 5 measuring generativity. The information investigation, championing and application were each measured with three items. Historic reliability and validity information, as provided above, were at an acceptable level.

\section{Participants}

In total, data were collected from 3180 respondents. After removing cases with missing data, as well as data sets with 
out-of-range data, 3096 cases remained. Participants represented the following race groups: Asian 8.4\%, black people $58.1 \%$, mixed ethnicity $8.4 \%$ and white people $25.1 \%$. The mean age for the group was 37.81 years, with a standard deviation of 9.10. In terms of schooling, $4.5 \%$ reported 'Less than 12 years schooling', $25.1 \%$ reported '12 years of schooling', 40.5\% reported '1st Degree/Diploma' and 29.7\% reported 'Higher Degree/Higher Diploma'. With regard to tenure, the mean tenure was 8.46 years, with a standard deviation of 7.45 years. In total, $36.3 \%$ of respondents reported that they held a managerial position. When reporting on being involved in the core business of the organisation, versus support services, $45.2 \%$ of respondents reported that they were involved in the core business of their companies.

\section{Analysis}

The analyses were performed with IBM SPSS Statistics (IBM SPSS Statistics 2017) and with the lavaan package (Rosseel 2012) in R ( $R$ Core Team 2013). Demographic data were generated first to define the sample. This was followed by descriptive data on the 14 items, including skewness and kurtosis. This was done to assess if the data did not diverge significantly from normality. The data did not diverge significantly.

Cronbach's alpha coefficients for the IWB were then calculated. This value, reported later, was deemed acceptable $(>0.90)$, which allowed for the analysis of the suitability of the data for factor analyses. Kaiser-Meyer-Olkin's measure of sampling adequacy $(\mathrm{KMO})$ and Bartlett's test of sphericity were performed and the results were acceptable, with KMO being excellent (>0.90 - [Field 2009]) and the Bartlett's test value being significant, and therefore acceptable (Pallant 2013). This allowed for the performance of exploratory factor analyses (EFA). Given outputs of the EFA, and particularly the strong one-factor solution suggested by the difference between the first and the second eigenvalue, the correlation between the factors of the EFA was calculated, as well as the Schmid-Leiman transformed solution, which reflects the direct relationships between the items with the general factor and the residualised group factors (Schmid \& Leiman 1957). The aforementioned did not provide comprehensive or conclusive results pertaining to the factorial structure of the IWB questionnaire; therefore, confirmatory factor analyses (CFI) were performed wherein five different fit models were tested. Figure 1 graphically presents the different models tested.

In Figure 1, combining (d) and (c) denotes a five-factor orthogonal model. Linking (d), (c) and (b) represents a correlated five-factor model. Joining (d), (c) and (a) represents a higher-order five-factor model. When adding (d) and (e), a single-factor model is presented and with (d), (c) and (e) a combined bi-factor model is attained.

As the $\chi^{2}$ statistic is no longer relied upon as a basis for the acceptance or rejection of model fit (Schermelleh-Engel,

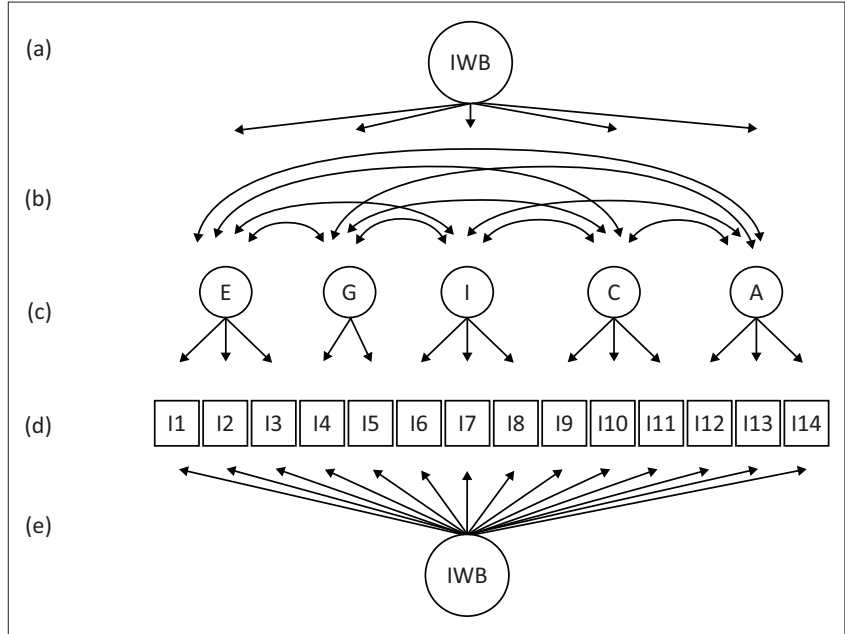

Note: II through 114 are items of the innovative work behaviour questionnaire. IWB, innovative work behaviour; E, exploration; G, generativity; I, information investigation; C, championing; A, application.

FIGURE 1: Measurement models for the innovative work behaviour.

Moosbrugger \& Müller 2003; Vandenberg 2006), it was not reported. Six measures of fit were reported on, namely, Comparative Fit Index (CFI), Tucker-Lewis Index (TLI), Akaike Information Criterion (AIC), Bayesian Information Criterion (BIC), Root Mean Square Error of Approximation (RMSEA) and Standardised Root Mean Square Residual (SRMR). Comparative Fit Index and TLI values greater than 0.95 were used as being indicative of a good model fit (Vandenberg \& Lance 2000). No specific cut-off values for AIC or BIC were specified and the rule of thumb was rather used, which states that the model with the lowest AIC or BIC value is the better fitting model (Schreiber et al. 2006; Van de Schoot, Lugtig \& Hox 2012). Some suggest a cut-off value for RMSEA < 0.08 (Van de Schoot et al. 2012), others RMSEA < 0.06 (Schreiber et al. 2006) while Awang (2012) and Hair et al. (2010) suggest that the model fit is acceptable when RMSEA $<0.05$. In this research, the more generous cut-off value for RMSEA $<0.08$ (Van de Schoot et al. 2012) was used. This fits in well with SRMR $<0.08$ seen as indicative of acceptable model fit, as suggested by Browne and Cudeck (1993).

\section{Ethical Consideration}

Ethical clearance to conduct this research was obtained from the Graduate School of Business Leadership at the University of South Africa, with ethical clearance number: 2014 SBL_018_CA.

\section{Results \\ Descriptive statistics}

The following are descriptive statistics of the scores on the individual IWB items, as well as the total scores.

From Table 1, it can be observed that the mean scores for Exploration (Items 1, 2, and 3) and Generativity (Items 4 and 5) were visibly higher than in the case of the other constructs. This may be interpreted as some ideas just remaining as ideas 
and not resulting in innovation. This aspect will be addressed in more detail in the discussion section. The skewness and kurtosis data indicate that the distribution of the data does not diverge from normality.

\section{Exploratory factor analysis}

The Kaiser-Meyer-Olkin measure of sampling adequacy was acceptable at 0.961 and Bartlett's test of sphericity yielded significant results $(p<0.001)$, which suggested that the data were factorable. Exploratory factor analysis was performed to test for the presence of a five-factor solution, as proposed by some literature. The results of the pattern matrix are presented below, where all items with a loading higher than 0.30 are bolded. Five factors accounted for $80.04 \%$ of the variance in the data.

From Table 2, it is evident that the structure created through EFA resembles the theorised structure well. Apart from item 12 , all the items loaded on separate factors, clustering with the items that measure the same sub-construct. For the fivefactor solution $\mathrm{RMSR}=0.01, \mathrm{TLI}=0.98$ and $\mathrm{RMSEA}=0.048$ (90\% CI: $0.042-0.053)$ indicated a good fit of a five-factor model. The BIC $=-0.86$.
However, the eigenvalues of the factors $(8.59,0.90,0.64,0.57$ and 0.56$)$ suggested a very strong general factor. To explore this possibility, the correlations between the factor loadings were calculated.

The range of the correlations was between 0.62 and 0.82 , which is relatively high (see Hair et al. 2010). This prompted testing for the extent to which a higher factor may explain the variance in the data. A Schmid-Leiman transformed solution (Schmid \& Leiman 1957), which transforms a higher-order factor solution into an orthogonal hierarchical solution with a general factor and residualised group factors was obtained. This solution reflects the direct relationships of the items with the general factor and the residualised group factors.

The general factor accounted for $80 \%$ of the common variance among the 14 items (explained common variance $=0.80$ ). This may be indicative that the general factor saturated the total score significantly. Against this background, a general factor model was tested, to assess the adequacy of just a general factor and no group factors. This yielded the following fit statistics: RMSR $=0.06, \mathrm{BIC}=2354.59$ and RMSEA index $=0.11(90 \%$ CI 0.107-0.114). As a whole, these

TABLE 1: Descriptive statistics.

\begin{tabular}{|c|c|c|c|c|c|}
\hline Item & Mean & Standard deviation & Skewness & Kurtosis & Standard error \\
\hline Item 1 & 4.09 & 1.22 & -0.10 & -0.66 & 0.02 \\
\hline Item 2 & 4.12 & 1.17 & -0.15 & -0.47 & 0.02 \\
\hline Item 3 & 3.76 & 1.16 & 0.03 & -0.29 & 0.02 \\
\hline Item 4 & 4.01 & 1.16 & -0.04 & -0.47 & 0.02 \\
\hline Item 5 & 3.97 & 1.17 & -0.12 & -0.36 & 0.02 \\
\hline Item 6 & 3.78 & 1.18 & 0.07 & -0.45 & 0.02 \\
\hline Item 7 & 3.63 & 1.20 & 0.15 & -0.38 & 0.02 \\
\hline Item 8 & 3.66 & 1.22 & 0.08 & -0.39 & 0.02 \\
\hline Item 9 & 3.74 & 1.24 & 0.02 & -0.49 & 0.02 \\
\hline Item 10 & 3.65 & 1.26 & 0.05 & -0.56 & 0.02 \\
\hline Item 11 & 3.63 & 1.23 & 0.03 & -0.49 & 0.02 \\
\hline Item 12 & 3.75 & 1.24 & -0.01 & -0.48 & 0.02 \\
\hline Item 13 & 3.62 & 1.20 & 0.08 & -0.32 & 0.02 \\
\hline Item 14 & 3.68 & 1.22 & 0.05 & -0.39 & 0.02 \\
\hline
\end{tabular}

TABLE 2: Exploratory factor analysis

\begin{tabular}{|c|c|c|c|c|c|c|}
\hline Item & Factor 1 & Factor 2 & Factor 3 & Factor 4 & Factor 5 & Commonalities \\
\hline Item 1 & 0.03 & 0.00 & $0.74 \dagger$ & 0.03 & 0.04 & 1.0 \\
\hline Item 2 & 0.00 & 0.01 & $0.92 \dagger$ & -0.02 & -0.02 & 1.0 \\
\hline Item 3 & 0.02 & -0.03 & $0.33 \dagger$ & 0.23 & 0.15 & 2.3 \\
\hline Item 4 & 0.02 & -0.01 & 0.00 & $0.92 \dagger$ & 0.00 & 1.0 \\
\hline Item 5 & -0.02 & 0.22 & 0.12 & $0.45 \dagger$ & 0.10 & 1.8 \\
\hline Item 6 & 0.00 & $0.71 \dagger$ & 0.09 & 0.09 & -0.02 & 1.1 \\
\hline Item 7 & -0.01 & $0.88 \dagger$ & 0.00 & -0.02 & 0.00 & 1.0 \\
\hline Item 8 & 0.16 & $0.58 \dagger$ & -0.04 & 0.04 & 0.13 & 1.3 \\
\hline Item 9 & $0.51 \dagger$ & 0.21 & 0.03 & 0.10 & 0.04 & 1.4 \\
\hline Item 10 & $0.88 \dagger$ & -0.01 & 0.04 & 0.04 & -0.05 & 1.0 \\
\hline Item 11 & $0.70 \dagger$ & 0.02 & 0.03 & -0.02 & 0.11 & 1.1 \\
\hline Item 12 & $0.41 \dagger$ & 0.10 & 0.04 & 0.01 & $0.31 \dagger$ & 2.0 \\
\hline Item 13 & -0.01 & 0.01 & 0.02 & 0.03 & $0.84 \dagger$ & 1.0 \\
\hline Item 14 & 0.21 & 0.11 & 0.08 & 0.03 & $0.49 \dagger$ & 1.5 \\
\hline
\end{tabular}

$\dagger$, Significant loadings, higher than 0.3 . 
results indicate that a general factor model does not adequately account for the covariances of the 14 items.

\section{Confirmatory factor analysis}

Confirmatory factor analyses were performed, focussing on variations of the five-factor solution. Five models were tested to assess which theoretical structure fitted the data best. Firstly, a five-factor model with correlated factors was tested (see Figure 1; $\mathrm{d}+\mathrm{c}+\mathrm{b}$ ). Next, a higher-order model was tested, specifying that the five factors load on a single higher-order factor (see Figure $1 ; d+c+a$ ). An orthogonal five-factor model was then tested (see Figure $1 ; \mathrm{d}+\mathrm{c}$ ). After that, a bi-factor model was tested - implying that the data could be explained by a single general factor and five residualised group factors (see Figure $1 ; \mathrm{d}+\mathrm{c}+\mathrm{e}$ ). Lastly, a single factor solution was tested (see Figure $1 ; \mathrm{d}+\mathrm{e}$ ). In Table 5, the item loadings related to the different models are presented. The factor loadings for each of the models are presented in Table 5.

Table 6 complements Figure 1 in explaining the different fit models as well as the items and residualised group factors included in the analyses. From Table 6, it can be observed that loadings were consistently high in all models, except for the bi-factor model, where the loadings on the general factor were high, but the loadings on the five group factors were consistently less salient. To test which of the theoretical structures fitted the data best, several fit statistics were calculated. These are presented below.

In Table 6, it can be observed that the orthogonal model, given CFI, TLI, RMSEA and SRMR, did not meet the requirement for acceptable fit. All the other models met the basic requirements of satisfactory fit. From the results in Table 6, it can be seen that the correlated fivefactor model and the bi-factor model competed well for the best fit, outperforming the higher-order and the single-factor models substantively. For the five-factor model and the bi-factor model, most of the statistics are identical, with AIC being lower (better) in the bi-factor model and BIC being lower (better) in the five-factor model. The Standardised Root Mean Square Residual was also lower for the five-factor model, which suggests better fit. The five-factor model was adopted as the best representation of the present data, as more parameters

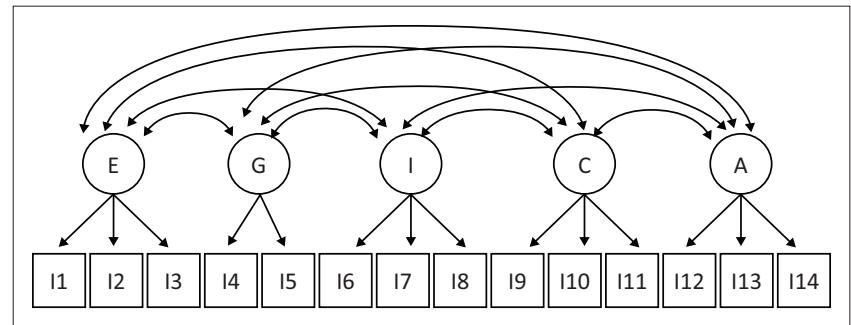

Note: II through 114 are items of the innovative work behaviour questionnaire. E, Exploration; G, Generativity; I, Information investigation; C, Championing; A, Application. FIGURE 2: Correlated five-factor model for the innovative work behaviour. indicated that the fit is best, but also as it represents a simpler model, which is mostly desirable.

\section{Discussion}

Having a clear understanding of what IWB entails is important as it relates to important organisational outcomes (Bos-Nehles et al. 2017; Sanz-Valle \& Jiménez-Jiménez 2018; Veenendaal 2015). Although most researchers interested in IWB conceptualise and measure IWB as a multi-stage process (De Jong \& Den Hartog 2010; Farr \& Ford 1990; Janssen 2000; Kanter 1988; Kleysen \& Street 2001; Scott \& Bruce 1994; West \& Farr 1989), they experience difficulty in trying to emulate these stages when applying factor analyses. Referring to Kleysen and Street's (2001) measure of IWB, neither these authors nor Hebenstreit (2003), Lu and Li (2010) or Wojtczuk-Turek and Turek (2013) could replicate the structure, reporting simpler models with factors. With regard to the De Jong and Den Hartog (2010) instrument, the same problems were experienced (see Atitumpong and Badir [2017], De Spiegelaere et al. [2014] and Niesen et al. [2018]). Scott and Bruce's (1994) explanation for realising less factors when testing measurement models of IWB, supported by De Jong and Den Hartog (2010), Janssen (2000), and Scott and Bruce (1994), is still unsubstantiated. The present study was therefore necessary, in order to shine some light on the matter, using more complex models to unravel relationships between the different elements of IWB.

In the present study, a large group of respondents (3096 employees), comprising both men and women, representative of the ethnic diversity of the South African workforce when considering Statistics South Africa requirements, completed the questionnaire. The collected data on the IWB questionnaire (Kleysen \& Street 2001) did not deviate meaningfully from the normal distribution and the Cronbach's alpha of 0.950 indicates high reliability.

An interesting fact emerges from the descriptive statistics, namely, that the scores for the first two constructs (Exploration and Generativity) are considerably higher than the scores for the following constructs (Information investigation, Championing and Application). This may suggest that more employees explore and generate ideas than those who make an effort to implement them. This intuitively makes sense, as it takes much more effort to implement an idea rather than coming up with one. This could also be a managerial concern, where management does not enable employees to voice or implement their ideas.

The EFA revealed a factorial structure in line with the structure suggested by Kleysen and Street (2001), with the exception of Item 12, which loaded on both Championing and Application (see Table 2).

Item 12 refers to '... implement(ing) changes that seem to be beneficial?' (Kleysen \& Street 2001:293). It could be that 
respondents interpreted this statement from a managerial perspective as championing, rather than from an operational perspective, as application, particularly as $36.3 \%$ of respondents reported that they held some managerial position. Despite the double loading of Item 12 , all the other items loaded in accordance with their theorised function.

The strong correlation between the factors extracted through EFA (see Table 3), the eigenvalues pointing to a single general construct and the reporting of a single construct by Hebenstreit (2003) necessitated testing for a general construct model. The Schmid-Leiman transformation was performed (see Table 4), with the general factor accounting for $80 \%$ of the common variance among the 14 items. The fit statistics revealed that the general factor model does not adequately account for the covariances among the items.

Using the lavaan package (Rosseel 2012) in R (R Core Team 2013), five competing factorial models were tested (see Table 5). The fit of the orthogonal model, suggesting that the factors are independent and unrelated, was very poor, which supports the theory that the elements of IWB are indeed related, given argumentum ad ignorantiam. However, four subsequent models in which the items and/or factors are related were tested. The weakest of these, by far, was the single factor solution, which was therefore excluded as a candidate for ideal fit. This finding is contrary to the findings of Kleysen and Street (2001) and Hebenstreit (2003), who theorised about the existence of separate factors, but who could statistically find only a single factor.

\begin{tabular}{lccccc} 
TABLE 3: Correlation among extracted factors. \\
\hline Factor & Factor $\mathbf{1}$ & Factor $\mathbf{2}$ & Factor 3 & Factor 4 & Factor 5 \\
\hline Factor 1 & 1.00 & 0.82 & 0.69 & 0.68 & 0.77 \\
Factor 2 & 0.82 & 1.00 & 0.72 & 0.74 & 0.72 \\
Factor 3 & 0.69 & 0.72 & 1.00 & 0.73 & 0.62 \\
Factor 4 & 0.68 & 0.74 & 0.73 & 1.00 & 0.62 \\
Factor 5 & 0.77 & 0.72 & 0.62 & 0.62 & 1.00 \\
\hline
\end{tabular}

After considering the remaining models (the higher-order five-factor, the bi-factor models and the correlated five-factor model), the bi-factor models and the correlated five-factor model yielded almost equal results. The correlated fivefactor model was accepted as the best fitting model, given the fit statistics being the best for most parameters. Also, in the competing bi-factor model, many items did not have significant loadings (see Table 6), while consistent high loadings were reported in the same table for the correlated five-factor model. Furthermore, simpler models are desirable, particularly where application is concerned (Aguilar-Savén 2004). The best fitting factorial structure for the IWB is presented below.

\section{Conclusion}

A correlated five-factor model explains the measurement fit of IWB as proposed by Kleysen and Street (2001) and appears to be superior to all other factorial models. This suggests that IWB indeed comprises separate but dependent sub-constructs. It has implications for those interested in enhancing IWB, as it could be possible to focus on specific aspects of the phenomena so as to foster its development as a whole. It also shows the relatedness of the different sub-constructs, echoing Scott and Bruce's (1994) notion that individuals performing IWB are involved in several of these activities simultaneously. This also has interventional implications, as fostering IWB should then not involve interventions at any specific part or at the start of the process (e.g. Exploration and Generativity), but also intervention at later stages of the process (e.g. Information Investigation, Championing, and Application), as they are all related. This makes sense if it is argued that an employee who has knowledge regarding how to implement ideas would also be more keen to generate them. Interventions at both these levels should thus be considered. Future researchers are encouraged to use IWB, as proposed by Kleysen and Street (2001), in their research as a five-factor correlated construct, as originally proposed by these authors.

TABLE 4: Schmid-Leiman solution.

\begin{tabular}{|c|c|c|c|c|c|c|}
\hline Item & General factor & Factor 1 & Factor 2 & Factor 3 & Factor 4 & Factor 5 \\
\hline Item 1 & 0.68 & - & 0.44 & - & - & - \\
\hline Item 2 & 0.72 & - & 0.55 & - & - & - \\
\hline Item 3 & 0.56 & - & 0.20 & - & - & - \\
\hline Item 4 & 0.76 & - & - & - & - & 0.54 \\
\hline Item 5 & 0.72 & - & - & - & - & 0.26 \\
\hline Item 6 & 0.78 & - & - & 0.30 & - & - \\
\hline Item 7 & 0.78 & - & - & 0.37 & - & - \\
\hline Item 8 & 0.79 & - & - & 0.24 & - & - \\
\hline Item 9 & 0.78 & 0.23 & - & - & - & - \\
\hline Item 10 & 0.80 & 0.40 & - & - & - & - \\
\hline Item 11 & 0.74 & 0.31 & - & - & - & - \\
\hline Item 12 & 0.76 & - & - & - & - & - \\
\hline Item 13 & 0.72 & - & - & - & 0.51 & - \\
\hline Item 14 & 0.77 & - & - & - & 0.29 & - \\
\hline
\end{tabular}


TABLE 5: Loading of the different items per model.

\begin{tabular}{|c|c|c|c|c|c|}
\hline Latent variable/Item & $\begin{array}{l}\text { Factor loading - } \\
\text { five-factor model }\end{array}$ & $\begin{array}{c}\text { Factor loading - } \\
\text { higher-order model }\end{array}$ & $\begin{array}{l}\text { Factor loading - } \\
\text { orthogonal model }\end{array}$ & $\begin{array}{l}\text { Factor loading - } \\
\text { bi-factor model }\end{array}$ & $\begin{array}{l}\text { Factor loading - } \\
\text { single factor model }\end{array}$ \\
\hline \multicolumn{6}{|l|}{ Exploration items } \\
\hline Item 1 & 0.828 & 0.827 & 0.820 & 0.439 & - \\
\hline Item 2 & 0.858 & 0.860 & 0.884 & 0.551 & - \\
\hline Item 3 & 0.627 & 0.621 & 0.590 & 0.213 & - \\
\hline \multicolumn{6}{|l|}{ Generativity items } \\
\hline Item 4 & 0.839 & 0.837 & 0.835 & 0.372 & - \\
\hline Item 5 & 0.822 & 0.824 & 0.826 & 0.367 & - \\
\hline \multicolumn{6}{|l|}{ Investigation items } \\
\hline Item 6 & 0.833 & 0.832 & 0.827 & 0.214 & - \\
\hline Item 7 & 0.840 & 0.841 & 0.873 & 0.500 & - \\
\hline Item 8 & 0.840 & 0.841 & 0.813 & 0.156 & - \\
\hline \multicolumn{6}{|l|}{ Championing items } \\
\hline Item 9 & 0.840 & 0.844 & 0.891 & 0.167 & - \\
\hline Item 11 & 0.805 & 0.800 & 0.798 & 0.219 & - \\
\hline \multicolumn{6}{|l|}{ Application items } \\
\hline Item 12 & 0.825 & 0.822 & 0.789 & 0.174 & - \\
\hline Item 13 & 0.792 & 0.794 & 0.817 & 0.391 & - \\
\hline Item 14 & 0.849 & 0.851 & 0.863 & 0.318 & - \\
\hline \multicolumn{6}{|c|}{ Innovation components } \\
\hline Exploration & & 0.837 & - & - & - \\
\hline Generativity & & 0.869 & - & - & - \\
\hline Investigation & & 0.947 & - & - & - \\
\hline Championing & & 0.949 & - & - & - \\
\hline Application & & 0.938 & - & - & - \\
\hline \multicolumn{6}{|l|}{ All innovation items } \\
\hline Item 1 & - & - & - & 0.683 & 0.698 \\
\hline Item 2 & - & - & - & 0.708 & 0.721 \\
\hline Item 5 & - & - & - & 0.739 & 0.744 \\
\hline Item 6 & - & - & - & 0.789 & 0.796 \\
\hline Item 7 & - & - & - & 0.780 & 0.794 \\
\hline Item 8 & - & - & - & 0.810 & 0.813 \\
\hline Item 9 & - & - & - & 0.811 & 0.815 \\
\hline Item 10 & - & - & - & 0.818 & 0.827 \\
\hline Item 11 & - & - & - & 0.760 & 0.769 \\
\hline Item 12 & - & - & - & 0.788 & 0.792 \\
\hline Item 13 & - & - & - & 0.731 & 0.745 \\
\hline Item 14 & - & - & - & 0.793 & 0.802 \\
\hline
\end{tabular}

TABLE 6: Fit statistics.

\begin{tabular}{|c|c|c|c|c|c|}
\hline Statistic & Five-factor model & Higher-order model & Orthogonal model & Bi-factor model & Single factor model \\
\hline$\overline{\mathrm{CFI}}$ & 0.982 & 0.975 & 0.609 & 0.982 & 0.916 \\
\hline TLI & 0.975 & 0.969 & 0.544 & 0.975 & 0.901 \\
\hline AIC & 107821.6 & 108031.1 & 119681.5 & 107813.7 & 109912.8 \\
\hline $\mathrm{BIC}$ & 108135.5 & 108314.9 & 119929.0 & 108139.7 & 110166.4 \\
\hline RMSEA & 0.053 & 0.060 & 0.227 & 0.053 & 0.106 \\
\hline RMSEA $90 \% \mathrm{Cl}$ & $0.048-0.58$ & $0.055-0.065$ & $0.223-0.321$ & $0.048-0.059$ & $0.101-0.111$ \\
\hline SRMR & 0.021 & 0.028 & 0.461 & 0.022 & 0.040 \\
\hline
\end{tabular}

CFI, confirmatory factor analyses; TLI, Tucker-Lewis Index; AIC, Akaike Information Criterion; BIC, Bayesian Information Criterion; RMSEA, Root Mean Square Error of Approximation; RMSEA 90\% Cl, RAMSEA 90\% confidence interval; SRMR, Standardised Root Mean Square Residual.

\section{Acknowledgements}

The authors are grateful for the assistance of the Master of Business Leadership class of 2014 for collecting the data and the Graduate School of Business Leadership Research Ethics Review Committee for allowing access to the data used in this study.

\section{Authors' contributions}

R.S. constructed the research as part of his doctoral degree and therefore wrote the concept paper. G.d.B. was the supervisor of the study and assisted in the statistical analysis and writing of the final article. 


\section{Funding information}

This research received no specific grant from any funding agency in the public, commercial or not-for-profit sectors.

\section{Data availability statement}

Data can be obtained from the authors upon reasonable request.

\section{Disclaimer}

The views and opinions expressed in this article are those of the authors and do not necessarily reflect the official policy or position of any affiliated agency of the authors.

\section{References}

Aguilar-Savén, R.S., 2004, 'Business process modelling: Review and framework' International Journal of Production Economics 90(2), 129-149. https://doi. org/10.1016/S0925-5273(03)00102-6

Amir, M.T., 2015, 'Innovative behavior as a multidimensional construct', Jurnal Manajemen Teknologi 14(1), 66-80. https://doi.org/10.12695/jmt.2015.14.1.5

Atitumpong, A. \& Badir, Y.F., 2017, 'Leader-member exchange, learning orientation, and innovative work behavior', Journal of Workplace Learning 30(1), 32-47. https://doi.org/10.1108/JWL-01-2017-0005

Awang, Z., 2012, Structural equation modelling using AMOS graphic, 1st edn., Universiti Teknologi MARA Press, Shah Alam.

Bos-Nehles, A., Renkema, M. \& Janssen, M., 2017, 'HRM and innovative work behaviour: A systematic literature review', Personnel Review 46(7), 1228-1253. https://doi.org/10.1108/PR-09-2016-0257

Browne, M.W. \& Cudeck, R., 1993, 'Alternative ways of assessing model fit', in K.A Bollen \& J. Scott Long (eds.), Testing structural equation models, pp. 1-9, Sage, Newbury Park, CA.

De Jong, J. \& Den Hartog, D., 2010, 'Measuring innovative work behaviour', Creativity and Innovation Management 19(1), 23-36. https://doi.org/10.1111/j.14678691.2010.00547x

De Spiegelaere, S., Van Gyes, G., De Witte, H., Niesen, W. \& Van Hootegem, G., 2014 'On the relation of job insecurity, job autonomy, innovative work behaviour and the mediating effect of work engagement', Creativity and Innovation Management 23(3), 318-330. https://doi.org/10.1111/caim.12079

Farr, J. \& Ford, C., 1990, 'Individual innovation', in M. West \& J. Farr (eds.), Innovation and creativity at work: Psychological and organizational strategies, pp. 63-80, Wiley, Chichester.

Field, A., 2009, Discovering statistics using SPSS, 3rd edn., Sage, London.

Hair, J.F., Black, W.C., Babin, B.J. \& Anderson, R.E., 2010, Multivariate data analysis, Prentice Hall, Upper Saddle River, NJ.

Hebenstreit, J.J., 2003, 'Nurse educator perceptions of structural empowerment and innovative behaviour', Structural Empowerment/Nursing Education Research 33(3), 297-301. https://doi.org/10.5480/1536-5026-33.5.297

IBM SPSS Statistics, 2017, IBM SPSS Statistics for Windows, Version 25.0, IBM Corp, Armonk, NY.

Janssen, O., 2000, 'Job demands, perceptions of effort-reward fairness and innovative work behaviour', Journal of Occupational and Organizational Psychology 73(3), 287-302. https://doi.org/10.1348/096317900167038

Javed, B., Bashir, S., Rawwas, M.Y.A. \& Arjoon, S., 2017, 'Islamic work ethic, innovative work behaviour, and adaptive performance: The mediating mechanism and an interacting effect', Current Issues in Tourism 20(6), 647-663. https://doi.org/10.1 080/13683500.2016.1171830

Kanter, R.M., 1988, 'Three tiers for innovation research', Communication Research 15(5), 509-523. https://doi.org/10.1177/009365088015005001
Kast, F.E. \& Rosenzweig, J.E., 1972, 'General systems theory: Applications for organization and management', Academy of Management Journal 15(4), 447-465.

Kleysen, R.F. \& Street, C.T., 2001, 'Toward a multi-dimensional measure of individual innovative behavior', Journal of Intellectual Capital 2(3), 284-296. https://doi. org/10.1108/EUM0000000005660

Levy, D., 1994, 'Chaos theory and strategy: Theory, application, and manageria implications', Strategic Management Journal 15(S2), 167-178.

Lin, H.-C. \& Lee, Y.-D., 2017, 'A study of the influence of organizational learning on employees' innovative behavior and work engagement by a cross-leve examination', EURASIA Journal of Mathematics, Science and Technology Education 13(1), 3463-3478. https://doi.org/10.12973/eurasia.2017.00738a

Lu, X. \& Li, P., 2010, 'The impact of learning culture on individual innovative behavior', in 2010 International Conference on Management and Service Science, Wuhan, China, August 24-26, 2010, pp. 1-4. https://doi.org/10.1109/ICMSS.2010.5577177

Lukes, M. \& Stephan, U., 2017, 'Measuring employee innovation', Internationa Journal of Entrepreneurial Behavior \& Research 23(1), 136-158. https://doi. org/10.1108/IJEBR-11-2015-0262

Niesen, W., Van Hootegem, A., Vander Elst, T., Battistelli, A. \& De Witte, H., 2018, 'Job Insecurity and innovative work behaviour: A psychological contract perspective', Psychologica Belgica 57(4), 174-189. https://doi.org/10.5334/pb.381

Pallant, J., 2013, SPSS survival manual, 5th edn., McGraw-Hill, Berkshire.

Polston-Murdoch, L., 2015, Innovative behavior in local government: Exploring the impact of organizational learning capacity, authentic leadership, psychological empowerment, and the moderating role of intrinsic motivation, Regent University School of Business \& Leadership, Regent University, Virginia Beach, VA.

R Core Team, 2013, R: A language and environment for statistical computing, R Foundation for Statistical Computing, Vienna, viewed 19 November 2018, from https://www.r-project.org/

Rosseel, Y., 2012, 'Lavaan: An R package for structural equation modeling', Journal of Statistical Software 48(2), 1-36, viewed 19 November 2018, from https://www. jstatsoft.org/article/view/v048i02

Sanz-Valle, R. \& Jiménez-Jiménez, D., 2018, 'HRM and product innovation: Does innovative work behaviour mediate that relationship?', Management Decision 56(6), 1417-1429. https://doi.org/10.1108/MD-04-2017-0404

Schermelleh-Engel, K., Moosbrugger, H. \& Müller, H., 2003, 'Evaluating the fit of structural equation models: Tests of significance and descriptive goodness-of-fit measures', Methods of Psychological Research Online 8(2), 23-74.

Schmid, J. \& Leiman, J.M., 1957, 'The development of hierarchical factor solutions', Psychometrika 22(1), 53-61.

Schreiber, J.B., Stage, F.K., King, J., Nora, A. \& Barlow, E.A., 2006, 'Modeling and confirmatory factor analysis results: A review', Journal of Educational Research 99(6), 323-337. https://doi.org/10.3200/JOER.99.6.323-338

Scott, S.G. \& Bruce, R.A., 1994, 'Determinants of innovative behavior: A path model of individual innovation in the workplace', The Academy of Management Journal 37(3), 580-607. https://doi.org/10.2307/256701

Statistics South Africa, 2018, Quarterly labour force survey, viewed 02 October 2018, from www.statssa.gov.za/publications/P0211/P02112ndQuarter2018.pdf

Teece, D.J., 2018. 'Dynamic capabilities as (workable) management systems theory', Journal of Management \& Organization 24(3), 359-368. https://doi.org/10.1017/ jmo.2017.75

Van de Schoot, R., Lugtig, P. \& Hox, J., 2012, 'A checklist for testing measurement invariance', European Journal of Developmental Psychology 9(4), 486-492. https://doi.org/10.1080/17405629.2012.686740

Vandenberg, R.J. \& Lance, C.E., 2000, 'A review and synthesis of the measurement invariance literature: Suggestions, practices, and recommendations for organizational research', Organizational Research Methods 3(1), 4-70.

Vandenberg, R.J., 2006, 'Statistical and methodological myths and urban legends', Organizational Research Methods 9(2), 94-201.

Veenendaal, A.A.R., 2015, 'Enhancing innovation at work through human resource management', University of Twente.

Von Bertalanffy, L., 1968, General system theory: Foundations, development applications, George Braziller, New York.

West, M.A. \& Farr, J.L., 1989, 'Innovation at work: Psychological perspectives', Social Behaviour 4(1), 15-30.

Wojtczuk-Turek, A. \& Turek, D., 2013, 'Innovativeness in organizations: The role of LMX and organizational justice: The case of Poland', Synergia International Journal of Synergy and Research 2(1), 41-55. 